\title{
Experimental Study on the Non-reacting Flowfield of a Low Swirl Burner
}

\author{
Hang Yin \& Ren Dai \\ School of Energy and Powering Engineering, University of Shanghai for Science and Technology \\ Box 25, 516\# Jungong Road, Shanghai, China \\ Tel: 86-139-1725-1930Ｅ-mail: yinhang36@163.com
}

Received: August 26, $2011 \quad$ Accepted: September 13, $2011 \quad$ Published: December 31, 2011

doi:10.5539/eer.v1n1p105 URL: http://dx.doi.org/10.5539/eer.v1n1p105

The work is supported by Shanghai Leading Academic Discipline Project (Project No. J505011).

\begin{abstract}
Lean premixed low swirl combustion is an effective way to control NOx emission. In the present work a low swirl burner fitting with vane swirler has been used to investigate the flowfield characteristics. Two swirlers $\left(65^{\circ}\right.$ and $40^{\circ}$ setting angle) have been adopted for velocity measurement by using PIV technique. The results show that the critical swirl number when recirculation zone appears scarcely changed with the swirler setting angle and central jet velocity, and the demarcation between high and low swirl flow can be set as 0.48 in this work. Compared to swirler II, a wider low speed zone and a more divergent flow emerge downstream swirler I. Dimensionless axial velocity profiles along central axis decline linearly and approximately come to zero at $\mathrm{x} / \mathrm{D}=1.37$ for swirler II and $\mathrm{x} / \mathrm{D}=1.56$ for swirler I. For two-dimensional turbulent kinetic energy profiles, two peaks downstream of the swirl mean higher burning velocity than central jet. And turbulent kinetic energy downstream swirler II is observed higher.
\end{abstract}

Keyword: Vane swirler, Setting angle, Low swirl, Swirl number, PIV

\section{Nomenclature}

$\begin{array}{llll}\text { PIV } & \text { particle image velocimetry } & \text { MFC } & \text { mass flow controllers } \\ \text { LDA } & \text { laser Doppler anemometry } & \mathbf{X} & \text { axial coordinate } \\ \mathbf{u} & \text { axial velocity } & \mathbf{r} & \text { radial coordinate } \\ \mathbf{v} & \text { radial velocity } & \mathbf{S} & \text { swirl number } \\ \mathbf{U}_{\mathbf{j}} & \text { jet velocity } & \mathbf{D} & \text { burner diameter } \\ \mathbf{Y} & \text { height above the burner } & \mathbf{k} & \text { turbulent kinetic energy }\end{array}$

\section{Introduction}

Swirl provides an effective means to control flame stability as well as combustion intensity. The recirculation zone produced by strong swirl is widely used to stabilize flames in gas turbine and boiler combustion chambers (Rankin, 2007; Linck, \& Gupta, 2009). However, NOx is generated more due to the increased residence time in fiery recirculation region, which falls to meet the more stringent control regulations on NOx emission. Therefore, several effective methods (e.g., fuel staging, autofeedback loop, exhaust gas clean up, catalytic assisted combustion) have been adopted to control NOx emission. However, these schemes need accurate control combustion process that lead to high expense (Cheng, R. K., et al., 2008). Lean premixed low swirl combustion is a simple method to reduced NOx emission (Cheng, R. K., et al., 2000; Johnson, M. R., et al., 2005). Moreover, low swirl burner provides ideal flames for the fundamental investigation of flame structure and combustion/turbulence interaction.

Chan (Chan, C. K., et al., 1992) firstly used a tangential air jet swirler to produce low swirl in methane premixed combustion. They found that recirculation zone doesn't exist in the flow field and flame is stabilized by flow divergence. Cheng (Cheng, R. K., et al., 2000) applied vane swirler to a low swirl burner for commercial 
application. With LDA, they concluded that the flowfield generated by vane swirler is almost in accordance to that generated by tangential air jet, and constant velocity criterion is valid for scaling burner diameter to achieve higher thermal outputs. A high swirl burner was modified to a low swirl burner by Johnson (Johnson, M. R., et al., 2005), comparison shows that two burners have almost the same load range, and low swirl flame stability is not affected by equivalence ratio, inlet temperature, pressure and central jet velocity. NOx emission is $60 \%$ lower than high swirl burner. Stability characteristics were investigated with four tangential jets at the same stoichiometry as the main jet (Mansour, M., \& Chen, Y. C., 2008). The burner was also used to measure the turbulent burning velocity and flame structure (Plessing, T., et al., 2000).

To the authors' knowledge no investigation currently exists that provides quantitative date at various swirler setting angles in the near-field region of a low swirl burner. In the present work, the non-reacting velocity fields have been measured with Particle Image Velocimetry technique, and flow characteristics are compared for two vane swirlers $\left(65^{\circ}\right.$ and $40^{\circ}$ setting angle) to gain better insight into the influence of swirler setting angle on the flowfield. Two main jet velocities at each setting angles have been selected for detailed velocity measurements. And the demarcation between high and low swirl is also discussed.

\section{Experimental}

The experiment system mainly includes gas supply system, burner and PIV system, as shown in Figure 1. Pressure regulating valve is used to control pressure of the compressed air from compressor. Downstream the valve, oil and water in the compressed air are removed by air filters with filtration accuracy up to $0.1 \mu \mathrm{m}$. Two MFCs $(500 \mathrm{~L} / \mathrm{min}$ and $1500 \mathrm{~L} / \mathrm{min})$ are used respectively to control the air flow rate of swirl and jet with accuracy of $0.5 \%$ f.s. $\mathrm{Al}_{2} \mathrm{O}_{3}$ powder with size of $5 \mu \mathrm{m}$ is used as tracing particle for good reflection and less influence on the autocorrelation calculation. As the study area is focused on the interaction part of jet and the swirl, tracing particle is only seeded in central jet flow through a particle generator.

PIV system is manufactured by TSI Inc. A 12-bit 4Mpixels CCD camera is controlled by the commercial Insight3G software (TSI) to run in a double exposure mode and to be synchronized with an Nd:YAG laser operated at $532 \mathrm{~nm}$. The time interval between two laser pulses is set to $80 \mu$ s for low-speed cases and $40 \mu$ s for high-speed cases. The scaling of collected Mie scattering images is determined as $128.04 \pm 0.05 \mathrm{pixel} / \mathrm{mm}$ from imaging a ruled target. The PIV paired images are processed with a cross-correlation algorithm within interrogation windows of $32 \times 32$ pixels at $50 \%$ overlap. A total of two hundred image pairs are recorded in each case to determine the mean velocity and turbulence properties.

The swirl burner structure shown in Figure 2 is axial symmetric. A central jet flow is surrounded with swirl flow produced by a swirler. 65 degree (Figure 3-a) and 40 degree (Figure 3-b) are selected as swirler setting angle, 5 and 12 vanes are arranged respectively. The thicknesses of swirler wall and guide vane are both $1 \mathrm{~mm}$, the height of vane is set as $4 \mathrm{~mm}$.

\section{Results}

Swirl strength is one of the most important factors to determine flowfield structure. Form Ref. (Littlejohn, D., \& Cheng, R. K., 2007), swirl number can be defined as

$$
S=\frac{2}{3} \tan \alpha \frac{1-R^{3}}{1-R^{2}+m^{2}\left((1 / R)^{2}-1\right)^{2} R^{2}}
$$

In this expression, $\alpha$ is setting angle, the ratio of the radii of inner diameter of jet flow and swirl flow, $\mathrm{R}$ is 0.83 , $m$ is the mass ratio of the jet flow and swirl flow.

According to a steady central recirculation zone in the flowfield, swirl flow can be divided into high swirl flow and low swirl flow. The critical swirl number thus can be defined as a special swirl number between low swirl and high swirl. Velocity measurements with different swirl numbers have been performed separately in all four cases (Table 1) to determine the critical swirl number. In this paper, only case 1 is used to interpret the determination of the critical swirl number. A divergent flowfield shown in Figure 4a forms downstream the swirl burner and the minimum velocity along central line is $0.2 \mathrm{~m} / \mathrm{s}$. With the increment of swirl intensity, the swirl number rises to 0.52 , the minimum velocity along central line falls below zero and a recirculation zone appears in Figure $4 \mathrm{~b}$. Therefore, the critical swirl number for case 1 can be considered as 0.51 .

The critical swirl numbers of all the cases are listed in Table.1. Obviously, weather the swirler setting angle or central jet velocity has little impact on the critical swirl number, and the demarcation between high and low swirl flow can be thought as 0.48 for the case in this work. Flow characteristics analysis of low swirl flow is carried 
out at the critical swirl number.

The flowfields of four cases (Figure 4a and Figure 5) show some uniform characteristics. No recirculation is found in flowfield, and a low speed zone forms downstream the burner exit. Close to burner exit $(\mathrm{x} / \mathrm{D}<1.5)$, flowfield are on the burner center axis of symmetry. Compared to swirler II , a wider low speed zone and a more divergent flow emerge downstream swirler I.

Dimensionless axial velocity profiles at different axial locations are plotted in Figure 6. To the same swirler setting angle, profiles of different central jet velocities behave quite similar and are symmetrical with respect to the burner central axis. As the axial distance increases, axial velocity decays quickly in favor of flame stabilization. Two peaks appear on both sides of the axis. With the increment of axial distance, the distance between the peaks increases for swirler I but almost keeps constant for swirler II. And a divergent low-speed area that is conducive to sufficient combustion forms downstream of the burner outlet.

Radial velocity profiles along central axis are mapped in Figure 7. Radial velocity profiles are on the burner center axis of symmetry and increase with the increment of central jet velocity. Radial velocity is not zero near the axis, which shows the effect of swirl has penetrated into jet flow center. As axial distance increases, peaks of the radial velocity firstly increase and then decrease. For the same central jet velocity, radial velocity of swirler I behaves higher than that of swirler II. And the distance between peaks of swirler I is also obvious larger which denotes a more divergent trend of flow.

Figure 8 shows dimensionless axial velocity profiles along central axis. Profiles of different central jet velocities have similar features, decline linearly and approximately come to minimum at $\mathrm{x} / \mathrm{D}=1.37$ for swirler II and $\mathrm{x} / \mathrm{D}=1.56$ for swirler I. Assuming the burning velocity is constant, shift of the combustible gas velocity would only alter stabilized position of flame, and the flame brush moves to upstream as the gas velocity decreases.

Two-dimensional turbulent kinetic energy profiles at different axial locations are given in Figure 9, and are on the burner center axis of symmetry. Two peaks downstream of the swirl mean higher burning velocity than central jet. With the increment of central jet velocity, peaks increase significantly. As axial distance increases, the peaks decrease quickly. Turbulent kinetic energy downstream swirler II is higher that means a faster combustion.

\section{Conclusions}

In the present work, a low swirl burner respectively fitting with $65^{\circ}$ and $40^{\circ}$ swirler is used to investigate the flowfield characteristics.

The critical swirl number when recirculation zone appears scarcely changed with the swirler setting angle and central jet velocity, and the demarcation between high and low swirl flow can be thought as 0.48 in this work.

Dimensionless axial velocity and radial velocity are all on the burner center axis of symmetry. For dimensionless axial velocity profiles, with the increment of axial distance, the distance between two peaks increases for swirler I but almost keeps constant for swirler II. For the same central jet velocity, radial velocity and the distance between two peaks of swirler I is higher than that of swirler II. Compared to swirler II, a wider low speed zone and a more divergent flow emerge downstream swirler I. Dimensionless axial velocity profiles along central axis decline linearly and approximately come to zero.

Two-dimensional turbulent kinetic energy profiles are on the burner center axis of symmetry. Two peaks downstream of the swirl mean higher burning velocity than central jet. Turbulent kinetic energy behaves higher downstream swirler II.

\section{References}

Chan, C. K., et al. (1992). Freely propagating open premixed turbulent flames stabilized by swirl. Twenty-Fourth Symposium (International) on combustion, 511-518. http://dx.doi.org/10.1016/S0082-0784(06)80065-2

Cheng, R. K., et al. (2000). Scaling and development of low-swirl burners for low emission furnace and boilers. Proceedings of Combustion Institute, 28, 1305-1313. http://dx.doi.org/10.1016/S0082-0784(00)80344-6

Cheng, R. K., et al. (2008). Laboratory studies of the flow field characteristics of low-swirl injectors for adaptation to fuel-flexible turbines. Journal of Engineering for Gas Turbine and Power, 130, 021501-1-10. http://dx.doi.org/10.1115/1.2795786

Johnson, M. R., et al. (2005). A comparison of the flowfields and emissions of high-swirl injectors and low-swirl injectors for lean premixed gas turbines. Proceedings of Combustion Institute, 30, 2867-2874. http://dx.doi.org/10.1016/j.proci.2004.07.040

Linck, M. B., \& Gupta, A. K. (2009). Twin-fluid atomization and novel lifted swirl-stabilized spray flames. 
Journal of Propulsion and Power, 25, 344-357. http://dx.doi.org/10.2514/1.35723

Littlejohn, D., \& Cheng, R. K. (2007). Fuel effects on a low-swirl injector for lean premixed gas turbines. Proceedings of the Combustion Institute, 31, 3155-3162. http://dx.doi.org/10.1016/j.proci.2006.07.146

Mansour, M., \& Chen, Y. C. (2008). Stability characteristics and flame structure of low swirl burner. Experimental Thermal and Fluid Science, 32, 1390-1395. http://dx.doi.org/10.1016/j.expthermflusci.2007.11.012

Plessing, T., et al. (2000). Measurements of the turbulent burning velocity and the structure of premixed flames on a low swirl burner. Proceedings of the Combustion Institute, 28, 359-366. http://dx.doi.org/10.1016/S0082-0784(00)80231-3

Rankin, D. D. (2007). Lean Combustion Technology and Control. (1st ed.). Burlington: Academic Press, (Chapter 5).

Table 1. The Critical swirl number

\begin{tabular}{|c|c|c|c|c|}
\hline Case & $\mathrm{C} 1$ & $\mathrm{C} 2$ & $\mathrm{C} 3$ & $\mathrm{C} 4$ \\
\hline Swirler setting angle & 65 degree & 65 degree & 40 degree & 40 degree \\
\hline Central jet velocity & $3 \mathrm{~m} / \mathrm{s}$ & $5 \mathrm{~m} / \mathrm{s}$ & $3 \mathrm{~m} / \mathrm{s}$ & $5 \mathrm{~m} / \mathrm{s}$ \\
\hline Critical swirl number & 0.51 & 0.49 & 0.51 & 0.48 \\
\hline
\end{tabular}

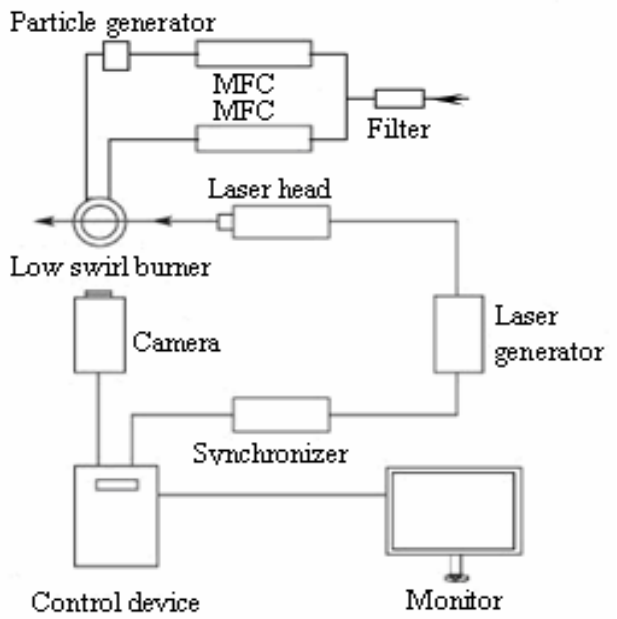

Figure 1. Schematic diagram of combustion experimental platform and PIV system

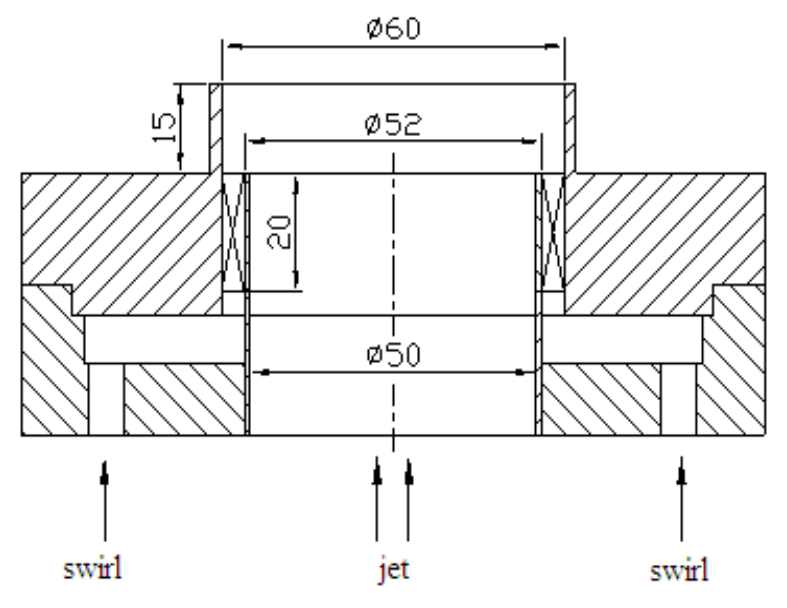

Figure 2. Schematic diagram of burner structure

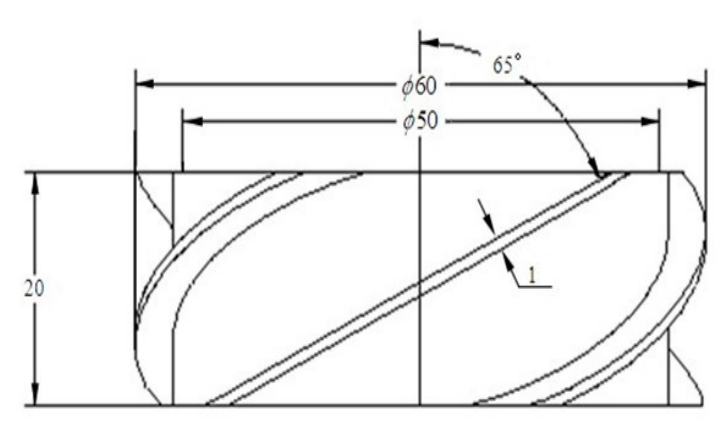

a. swirler I $\alpha=65^{\circ}$

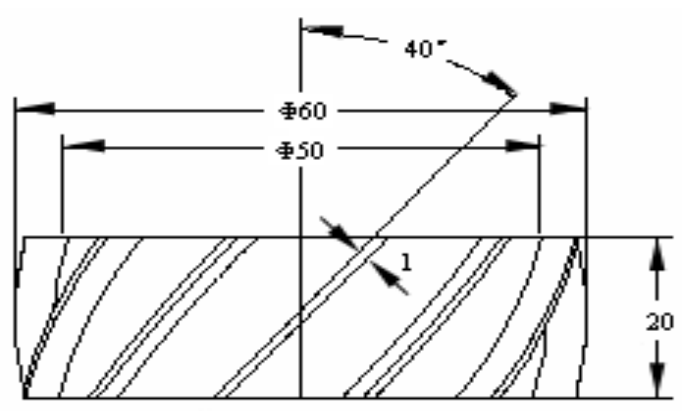

b. swirler II $\alpha=40^{\circ}$

Figure 3. Schematic diagram of swirler structure 


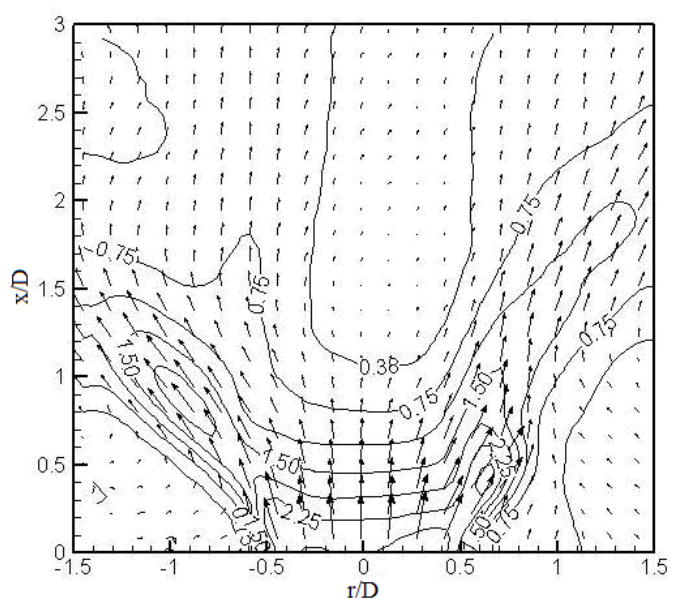

a. $\mathrm{S}=0.51$

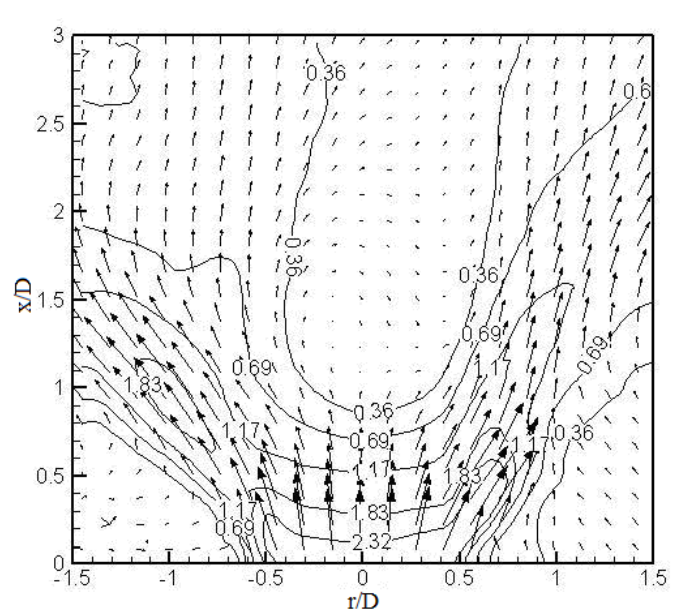

b. $S=0.52$

Figure 4. Flowfield of different swirl numbers for case 1

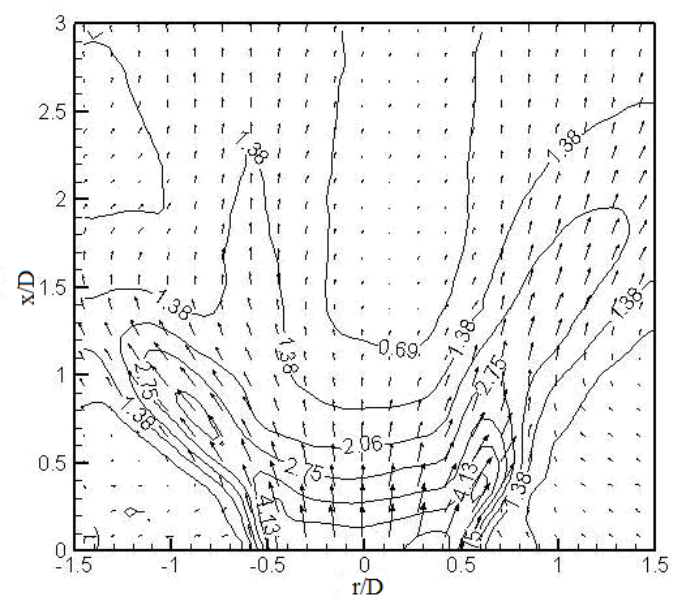

a. $\alpha=65^{\circ}, U j=5 \mathrm{~m} / \mathrm{s}, S=0.72$

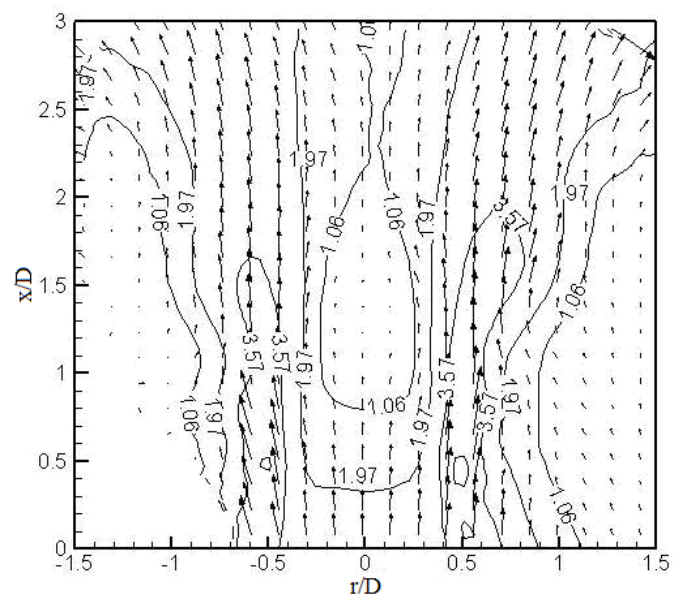

b. $\alpha=40^{\circ}, U j=3 \mathrm{~m} / \mathrm{s}, S=0.60$

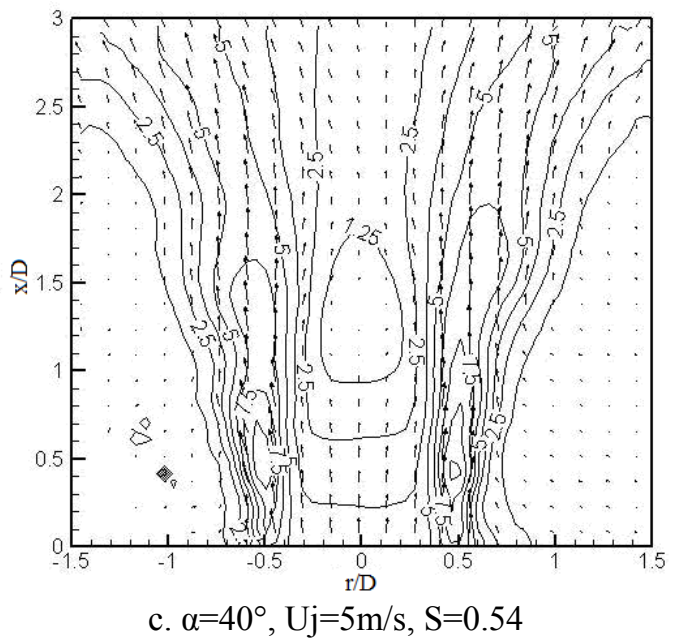

Figure 5. Vector and velocity isoline of low swirl flowfield 


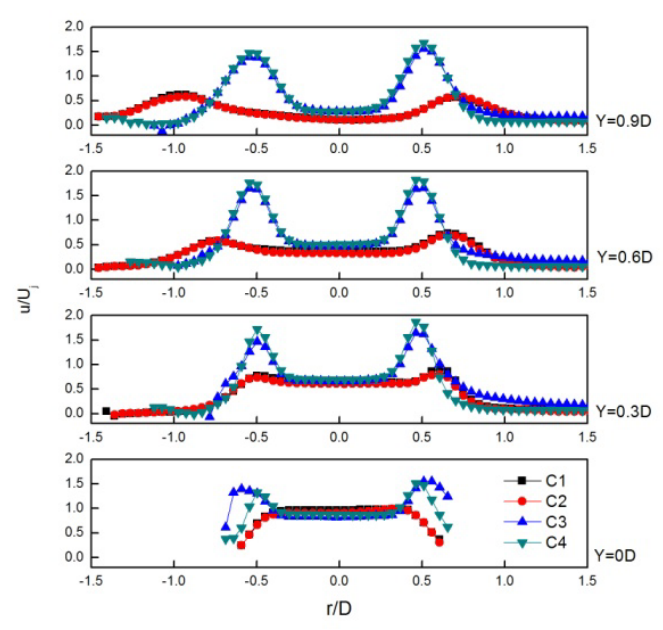

Figure 6. Dimensionless axial velocity profiles at different axial locations

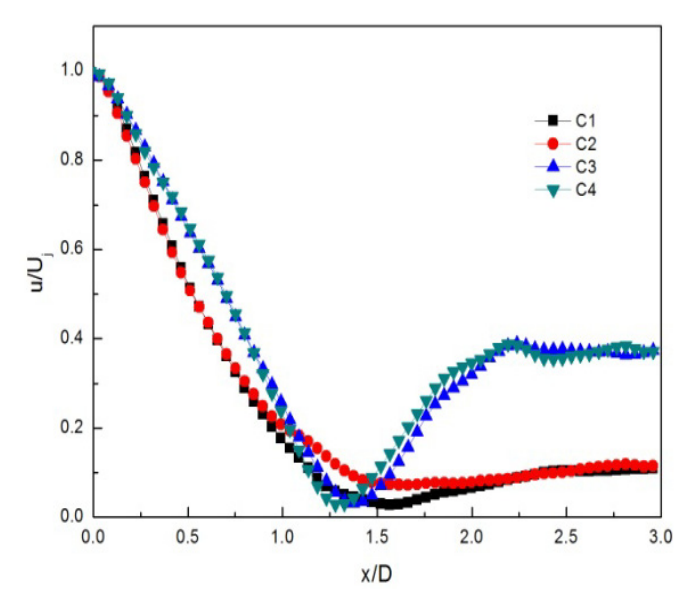

Figure 8. Dimensionless axial velocity profiles on central axis

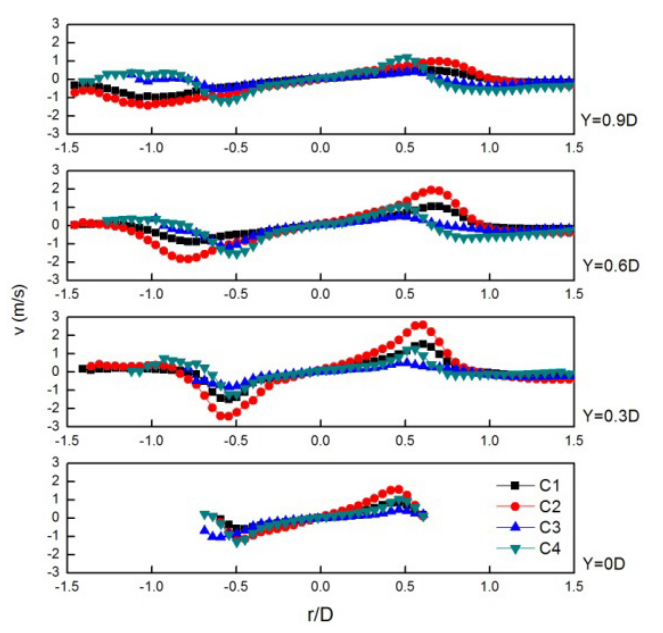

Figure 7. Radial velocity profiles at different axial locations

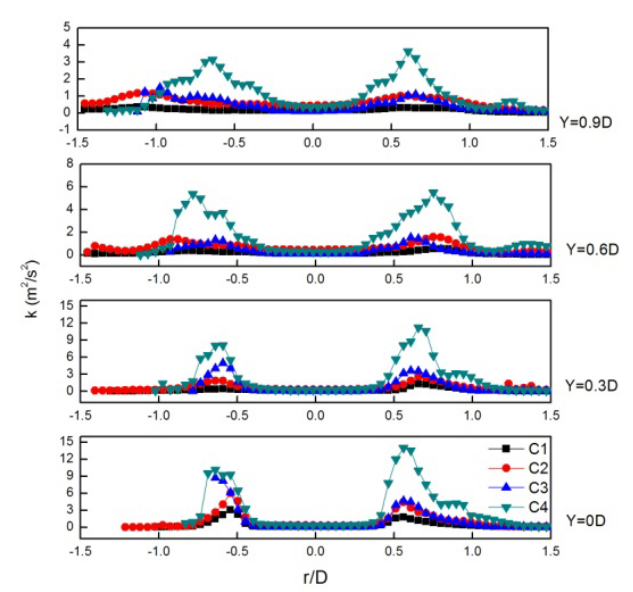

Figure 9. Turbulent kinetic energy profiles at different axial locations 